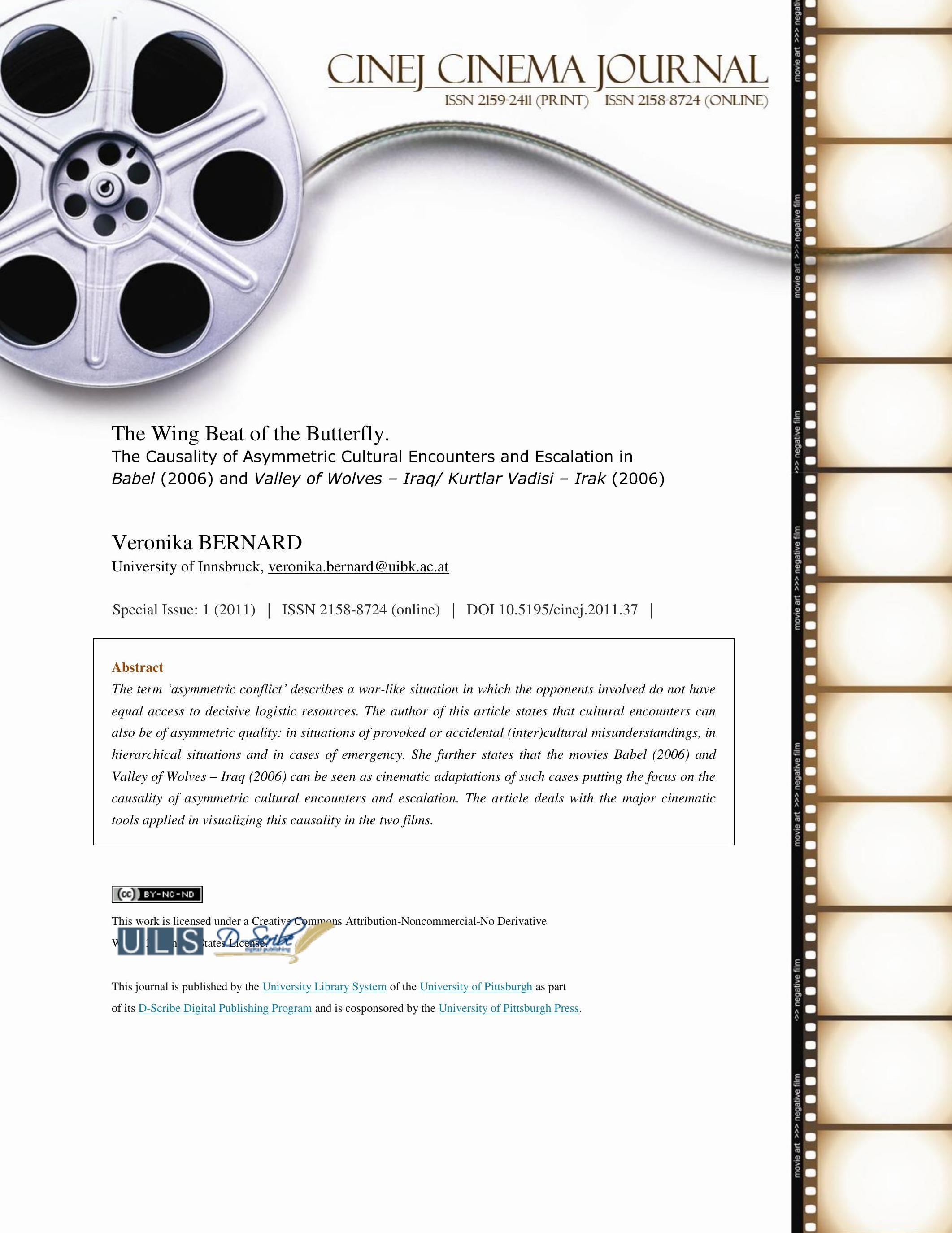




\section{The Wing Beat of the Butterfly. The Causality of Asymmetric Cultural Encounters and Escalation in Babel (2006) and Valley of Wolves - Iraq/ Kurtlar Vadisi - Irak (2006)}

\section{Introduction - Babel and Valley of Wolves: Two Political Films of 2006}

Although being received by the public very differently ${ }^{1}$, Mexican born director Alejandro González Iñárritu's film Babel and Turkish director Serdar Akar's production Valley of Wolves - Iraq have at least two aspects in common: They can be seen as political films, and they take the perspective of those being or feeling disprivileged and victimized by situations of asymmetric cultural encounters ${ }^{2}$.

Babel catches the post-9/11 political climate dominated by the US war against terrorism in telling five days in the lives of four families living at opposite ends of the world. When a shot fired to test a newly bought gun in the Moroccan mountains accidently hits a US American woman (Susan [Jones]; starring Cate Blanchett) this incident snowballs. During the following five days it not only sends the machinery of international media and US diplomacy to action it also decisively influences the lives of those whose stories are told by the film: a US couple, whose male spouse ( Richard [Jones]; starring Brad Pitt) is trying to mend their marriage on a journey to Morocco, and whose female spouse is the one being hit by the shot on the second last day of their journey; the couple's (illegal) Mexican maid (Amelia; starring Adriana Barraza) and her nephew (Luis; starring Robert Esquivel); a Japanese widowed businessman (Yasujiro; starring Koji Yakusho), who gave the gun used in the incident to his Moroccan hunting guide years ago, and his deaf teenage daughter (Chieko; Rinko Kikuchi), who blames her father for her mother's suicide; and a Moroccan peasant family, whose younger son (Ahmed; starring Said Tarchani) is the one who fires the shot while tending the family goats on a hillside and by chance hits the US American woman travelling with her husband in a tourist bus just passing by. This situation severely affects the US couple's Mexican maid Amelia back home in the US. During the couple's absence she has been in charge of the couple's infant children Mike and Debbie (starring Nathan Gamble and Elle Fanning). As the couple does not return home in time for her to go and see her family in Mexico for her son's wedding she is caught in a dilemma and finally takes the children to Mexico. When her nephew Santiago (starring Gael Garcia Bernal) takes them back to the US by car in the night after the wedding although he is drunk they are held up by US border control because they are lacking written allowance for the trip by the children's parents. When Santiago panics and drives off they are chased by police. ${ }^{3}$ After being dropped together with Mike and Debbie in the nightly desert by Santiago who drives off alone, ${ }^{4}$ Amelia and the children end up walking the desert in burning sunlight and close to fatal dehydration the following day before they are finally rescued by US border patrol people. ${ }^{5}$ The Japanese father's and daughter's story focuses on Chieko's personal problems after her mother's suicide, which she tries to drown in consumerism, alcohol, drugs, by provoking people and by testing her sexual attraction on men just to be rejected by each of them and feeling even more inferior and humiliated afterwards. ${ }^{6}$ Towards the end of the film it is suggested that the mother's suicide has been committed with the very gun the Japanese had given to his Moroccan guide afterwards. ${ }^{7}$

This context given, the film ends in taking a pessimistic and disillusioning perspective by sending the (materially and socially) privileged back to their (originally) good and privileged lives of love and harmony; by showing the (materially and socially) dis-privileged being even more victimized than before; and by showing 
those having caused the escalation getting away with it: Susan Jones is taken to a Casablanca hospital by a NATO/ Red-Cross helicopter after having re-united with her husband and finally is released from there five days later under massive international press coverage ${ }^{8}$ the Japanese father and daughter find together again after a long time of inner separation. ${ }^{9}$ Amelia is being expelled from the US for being an illegal immigrant and is shown sitting on a Mexican street side with the rest of her belongings waiting to be picked up by her son while her nephew has managed to escape arrest by US border patrol; ${ }^{10}$ and the Moroccan family's elder son Yussuf (starring Boubker Ait El Caid) is shot by police while his younger brother Ahmed who also caused this further escalation by shooting a policeman on their flight to the mountains lives and is shown destroying the gun as the source of all evil in desperate anger and handing himself in to the police. ${ }^{11}$

Valley of Wolves - Iraq takes an authentic political incident for a starting point of its cinematic adaptation of the 2003 US invasion of Iraq: Its pre-titles sequence shows a Turkish military officer referring to the Turkish-US Sülemaniye hood affair of $2003^{12}$ in a letter to a friend before committing a suicide for having failed in protecting his comrades in this incident and seeing them like his superior and himself being arrested. ${ }^{13}$ This political message is supported by the ideologically inverted east-west foe-and-hero pattern, which the narrative of the film relies on and which borrows its hero from a popular weekly Turkish TV serial titled Kurtlar Vadisi, ${ }^{14}$ and by integrating semi-authentic material to the film, like the cinematic adaptations of the US torture photos shot at Baghdad's Abu Ghraib prison.

The hero of the film is Polat Alemdar (starring Necati Şaşmaz), a Turkish undercover secret agent acting in the grey zone between legality and illegality. He is the military officer's friend to whom the letter is addressed and who is asked to fight for his and the officer's honour, i. e. to find the person to be held responsible for the disgrace the officer has suffered and to seek satisfaction for his suicide. This person is a US American named Sam William Marshall (starring Billy Zane), who by status is a civilian seeing himself as a member of the US forces, though, and understanding his presence in Iraq as kind of a personal mission to free the land of his forefathers. ${ }^{15}$ The two men's attempts to kill each other form one strand of the narrative. The other strand tells Leyla's story: Leyla (starring Bergüzar Korel) is the Iraqi heroine of the film and a peaceful Sheik's (Abdurrahman Halis Kerkuki; starring Chassan Massoud) adopted daughter, who is shown losing her husband on their wedding night due to a US provoked attack on the wedding ordered by Marshall ${ }^{16}$ and who is seeking to revenge on Marshall for this loss. In the course of the film she joins forces with the Turkish hero before she is shot by Marshall in the finale.

The ending of Valley of Wolves - Iraq sends a mixed message to audiences similar to that of Babel: Leyla's father, the integrative Sheik, is dead after he has been missiled by Marshall in his mosque during the morningprayer; ${ }^{17}$ Alemdar is shown desperately mourning over the dying Leyla he has not been able to protect. ${ }^{18}$ In contrast to Babel, though, the ones causing the escalation have not been able to get away: Marshall and his unscrupulous assistant Dante (starring Diego Serrano) are both dead; Marshall is stabbed by Alemdar using Leyla's dagger, ${ }^{19}$ giving her and his dead friend satisfaction by this; and Dante is stabbed by Leyla. ${ }^{20}$ However, the Turkish hero and his mates have only fulfilled and survived their mission because they have fought their opponent using his own means, i. e. using violence and killing others.

\section{The Subject of the Article - The Visualization of the Causality of Asymmetric Cultural Encounters and Escalation}

In structuring and visualizing these narratives both, Babel and Valley of Wolves - Iraq, exploit the principle of chaos theory ${ }^{21}$ : The causalities created all start at single incidents of a-symmetric cultural encounters whose consequences are not to be foreseen and which result in a series of other incidents producing further unforeseen 
incidents. Although using the same structural pattern of causality the two films, nevertheless, take essentially different ways in linking the featured stream of escalation to the sparking situations of asymmetric cultural encounters. While Babel integrates such situations in the flow of the individual narrative strands which have been initiated by a past (and just tell-told) situation of a-symmetric cultural encounter to visualize the dramatic and ironic development of the escalating process, Valley of Wolves - Iraq strategically visualizes them as the starting points of escalation. By focusing on selected theme setting scenes of the two films the article explores in how far the narrative structure of the films and the character drawing are part of these essentially different ways of visualizing the causalities created.

\section{The Narrative Structures of Babel and Valley of Wolves and their Visualization}

As far as the narrative structure of Babel is concerned the title of the film can be seen as the first key to understanding. The name "Babel" alludes to the Biblical image of the ancient megacity characterized not by its fruitful variety of tongues but by a contra-productive and destructive confusion of tongues: People communicate in their individual tongues and within their individual communities but the communities lack the ability of mutual communication. The imagery of the finale of the film can be seen as the second key: When the Japanese father returns home on the night of the very day when Susan Jones is released from the Moroccan hospital he finds his daughter Chieko naked on the balcony of his $31^{\text {st }}$ floor Tokyo penthouse flat looking over the illuminated city. Fear, surprise, and astonishment showing on his face he walks over to his daughter who moves her face, takes his hand and starts crying. When he takes her in his arms to calm her and when she allows him to do so the camera slowly starts moving backwards, and doing so for the following 50 seconds first shrinks the two people on the balcony, next the building and finally the city to invisible spots in a nightly black universe; indicating their existence to be known but human physical capacities of perception not being able to tell their exact position; while at second 40 of the finale the dedication by the director saying "To my children Maria Eladia and Elisio... the brightest lights in the darkest night" appears in the upper right hand corner. ${ }^{22}$

In line with these conceptual statements Babel creates a world of parallel actions from the very beginning, which are linked by a past accidental incident of a-symmetric cultural encounter but whose protagonists never directly meet within the period of time shown by the film; the parallel quality of actions being visualized by exploiting the jump cut technique at its very best. By literally forcing audiences to "jump" from the Japanese strand of the narrative into the Moroccan and Mexican one without a warning the film confronts viewers with presumably independent scenes, dialogues and images. It is not until the end of the film that audiences have learned scene by scene, dialogue by dialogue and image by image in which way the several scenes, dialogues and images are linked and are to be seen as individual perspectives taken on the sequences of a narrative whole. So, at the beginning of the film audiences hear the phone conversation between a man called "Sir" (Richard Jones) and a Mexican woman named Amelia (the Jones' maid) from Amelia's end and from Mr. Jones' son's end without knowing when exactly this phone call is taking place. You just hear a vague voice in the far telling "Amelia" that she can go and that someone will come to take care of the children in the evening and that his wife has to be operated on; ${ }^{23}$ you do not even know that this voice belongs to Richard Jones. The finale of the film then shows him making the very phone call from the hospital in Casablanca on his wife's delivery there and while waiting for

his wife to be operated on. ${ }^{24}$ Audiences see this while they already have knowledge of Amelia's expulsion from the US to Mexico and of the incidents leading to this. In this way audiences see the causalities of events unfold from their ends; the film stressing the inevitability of events and underlining people's powerlessness and 
impotence in influencing the escalating processes by this: Although being affected by the events people are not (actively) part of them.

The narrative structure of Valley of Wolves - Iraq relies on a pattern of confrontation, which sends characters into face-to-face encounters both with the several theme setting scenes and as far as the two narrative strands of the film (Alemdar's mission and Leyla's story) as a whole are concerned.

The narrative strand dealing with Alemdar's mission is initiated by the theme setting flashback pre-titles sequence showing the first (inter)cultural misunderstanding of the film lead into lethal escalation: Visualizing the sentences the Turkish military officer is just writing in his farewell letter addressed to Alemdar and opening "Sevgili Kardeşim" (My dear/ beloved brother) audiences see Marshall intrude on the Turkish Sülemaniye post in the cinematically adapted Sülemaniye hood affair scene and commit an (unfriendly) violation of the laws of hospitality by this as he "has been drinking tea" with the Turkish before. After meeting the Turkish military officer in charge face-to-face he orders the Turkish soldiers to be arrested and be led to the US van with sacks pulled over their heads so their faces cannot be seen and identified by others. ${ }^{25}$ This decision made by Marshall to protect the soldiers' honour and dignity is understood just to the opposite by the soldiers affected and by this starts the escalating process to come: Having to wear the sacks over their heads makes the soldiers lose their faces twice at a time - literally because the sacks are hiding their faces and figuratively because being led off with their faces hidden is seen as a disgrace.

The narrative strand dealing with Leyla's story starts when viewers see her father, the Sheik, prepare her and her husband-to-be for the wedding, ${ }^{26}$ and it first escalates in the theme setting scene showing the US intrusion on this wedding being "legitimized" by another (intercultural) misunderstanding; this time a provoked one, however: While the wedding festivity is starting audiences see two of Marshall's men watching the building, chewing gum and chatting; the one of them telling the other that the people at the wedding will soon start firing their guns and that this will be the moment for attack ${ }^{27}$ - the celebration shots fired by the wedding guests being deliberately seen as aggressive acts aiming at the US forces.

As soon as the two narrative strands meet in the scene when Leyla offers Alemdar and his mates hiding in her aunt's house on their flight from Marshall's men, ${ }^{28}$ and in the following fuse into one narrative strand, the narrative develops towards its climax and finale. In contrast to Babel, the viewers see escalation come with this suspense building technique.

The jump cut technique, which in $\underline{B a b e l}$ is used to visualize the separation of lives affected and the multitude of incidents caused by the initial incident, with Valley of Wolves - Iraq serves two purposes: the purpose of supporting the creation of suspense and visualizing escalation; and the purpose of creating continuity between the fictionalized cinematic world and reality. The scene showing the US intrusion on the wedding illustrates the first purpose: A jump cut separates the scene showing Marshall's men waiting outside the building from the next one showing them check IDs inside the building. The next jump cut appears after a little boy has walked towards one of them and has put a little stick, which he has taken from one of the music instruments, into the mouth of the soldier's gun pointing his direction: You see the boy lying on the ground shot and a wild shooting going on leaving several people dead - the jump cut leaving exactly this part of the scene open to the viewers' imagination which would provide clarity if the shot killing the boy was an accident caused by the little stick (the flower) or a shot fired on purpose by the US American. ${ }^{29}$ The second purpose shows whenever semi-authentic material is inserted to the narrative strands of the film; integrating Leyla's, Alemdar's and Marshall's fictitious stories into the historical reality of the US war in Iraq. 


\section{The Character Drawing in Babel and Valley of Wolves - Iraq and its Relevance for the Visualization of the Asymmetric Cultural Encounters and Escalation}

In line with this basic structural difference, Babel concentrates on the characters' communication habits as the central aspects of their personalities in illustrating the irony of events in its relation to a-symmetric cultural encounters; while Valley of Wolves - Iraq focuses on dress codes, attitudes towards honour, duty, violence, and the opposite sex with character drawing in supporting the visualization of asymmetric cultural encounters leading into escalation.

Babel, following its narrative structure of parallel actions, creates characters whose individual communicative and cultural habits make them representatives of worlds which are suggested to be separated by invisible walls of communicational and (inter)cultural in-competencies. The most significant scene illustrating this general pattern of character drawing is the one showing the tourist bus carrying the hit Susan Jones and the rest of the multi-national tourist group into the nearest village; the camera catching the situation both from the perspective of the tourists sitting inside the bus and starring through the glass of the bus windows at the villagers outside, who for their parts are following the bus and starring at its passengers through the same bus window glass; ${ }^{30}$ the glass functioning as a transparent, i. e. a visible and at the same time invisible, wall between their cultures (resembling a vertical version of a glass-ceiling), and the perspective taken from inside the bus suggesting a feeling of uncomfortable insecurity and of being trapped in a situation of incalculable risk shared by the passengers and Susan Jones in particular. Even when she is carried out of the bus and through the village into one of the huts this virtual wall is still there, being indicated by her panicking reluctance to be taken to the hut, put on the ground there, and finally by putting up a fierce resistance against allowing a veterinarian from nearby as the only doctor available to close the wound on her shoulder with an ordinary thread and a needle sterilized over open fire to avoid further loss of blood and inflammation. ${ }^{31}$

Suggesting that the escalation visualized in the film roots exactly in this (invisible) separation of cultural positions, and this being the underlying irony of events the narrative of the film is conveying, the central characters are designed to form culturally significant groups. There is the group of the angry young people represented by Chieko, who lives a life of time-killing activities covering her (personal and cultural) uprooting; and by Luis, who likes provoking and also shocking people, and is full of anger against US Americans for their discrimination of Mexicans and immigrants in general, which he articulates in sarcastic joking; besides he makes a slightly irresponsible impression which he shares with Ahmed, the younger son of the Moroccan peasant family; this one, in addition, showing suggested traits of moral inferiority, precocity, and irresponsibility when peeping on his naked sister, ${ }^{32}$ masturbating while tending the goats ${ }^{33}$ and choosing vehicles passing by on a road for targets to test a gun ${ }^{34}$. Another group is formed by the characters suggested to be morally integer; with this one you find the Moroccan peasants' elder son Yussuf who shows moral superiority when scolding Ahmed for his behaviour against their sister, and Amelia who willingly accepts hierarchies as naturally given, takes responsibilities, and tries to improve her living conditions by hard and honest work. Still another group is formed by the characters who are introduced as the representatives of cultural hegemony; as there is the Japanese businessman adopting traditional $19^{\text {th }}$ century colonial customs when going on a hunting trip to a far off place and giving his gun to his guide for a present; and there is Susan Jones, who is introduced as the (stereo)typical Westerner afraid of anything not belonging to her/ his familiar cultural community and seeing dangers everywhere; in a lack of hygiene in places like Morocco and in Mexican people; the significant theme setting scene with this being the one when she

192

CINEJ Cinema Journal: Vedat AKMAN

Special Issue: 1 (2011) | ISSN 2158-8724 (online) | DOI 10.5195/cinej.2011.37 | http://cinej.pitt.edu 
is sitting at some rural Moroccan street restaurant where the tourist group has stopped for lunch, ordering a diet coke, reluctantly and nerved accepting a normal coke when there is no diet coke available, next barking at the guy at her table (her husband Richard as audiences learn later) to throw away the ice in his glass as soon as the drinks are served because she is suspicious of the water quality, and, finally, furiously taking his glass away from him throwing the ice on the ground when he does not worry and is reluctant to do so, intending to use the ice to cool his drink instead. ${ }^{35}$ Finally, there is the group formed by the characters communicating with all cultural groups they get into contact with. As part of this group you find Richard Jones, who just manages the situation of emergency by asking people very openly for help and accepting their help, ${ }^{36}$ even though also he is shown not to be fully able to leave his cultural context when he offers the guide money for his help in the end; ${ }^{37}$ apart from him also the tour guide and the old Moroccan peasant woman, who both simply help, are part of this group.

These character drawings are integrated in the underlying concept of irony, escalation and victimizing: The irony being that the morally integer ones are shown to be the ones who are victimized, as is suggested by Amelia's and Yussuf's stories; the morally dubious "angry young men", who feel victimized, being the ones victimizing others by their escalating actions; and the central character Susan Jones, whose hegemonic attitude has been introduced as rooting in deep fear of the other, being shown to become the one forced into a situation of emergency and into a position of being dependent on the help and support of exactly those ones she is fearing so badly and is looking down upon so much for their supposed cultural inferiority: If she wants to survive she has to accept the Moroccan villagers' help and the supposedly unhygienic surroundings - and the opium pipe which the old Moroccan woman had in her mouth to start it and next offers her to calm her down and send her to an at least shortly relaxing sleep. ${ }^{38}$

In this way the character drawing helps further specify the suggested context of escalating asymmetric cultural encounters: The cultural groups involved are not shown to be identical with cultures in a traditional understanding of the term, like nation cultures. It is the individuals sharing certain patterns of behaviour and coming from different nations, speaking different languages and belonging to different religious communities who form the cultural groups relevant in the escalating processes shown in the film; the relevant patterns of behaviour being linked to certain (universal) social contexts and indicating them to be of both universal and individual quality instead.

Valley of Wolves - Iraq creates two central (male) characters representing opposing cultural hemispheres: the Turkish hero Alemdar and his US opponent Marshall. Alemdar's character drawing together with that of the other Turkish and Iraqi characters shapes an (Eastern) world in which a man's honour and his duty are central values. Marshall is presented as the representative of a morally inferior world in which people of Marshall's kind are aiming at establishing and increasing power by money, technological superiority and by exclusively devoting man's intellectual potential to scheming, plotting and cheating at the disadvantage of others: individuals, states and cultural communities.

The surface indicator of the two hemisphere's incompatible codes of values is the central characters' dress codes. As professionals both are shown to wear suits on the job. Marshall's choice of suit, however, makes him appear over-dressed for the occasion and by this suggests moral decadence: He either wears a casual beige or an elegant white suit, no matter if he comes to arrest the Turkish soldiers in the pre-titles sequence of the film or watches US soldiers violently intrude on an Iraqi wedding ceremony from his car while on his way to some Kurdish ceremony honouring him. ${ }^{39}$ Besides, the film shows Marshall not changing for his free time activities: He is wearing the very suit at his apartment when playing the piano. ${ }^{40}$ This suggests him to be constantly on his mission. Alemdar changes from job to private: When the job with its sometimes dirty work is done, he turns into the private person he is by changing. This change of clothes also indicates the Turkish hero as taking a time-out on 
his mission and it suggests that it would be unfair for Marshall to attack now; the hero will be still alert but not properly armed. The finale of the film exploits exactly this suggestive message of the dress codes to ultimately highlight Marshall's moral decadence: When Alemdar goes to the mosque at the time of the morning-prayer to leave the Sheik's daughter Leyla there he is wearing a T-shirt under a windcheater. ${ }^{41}$ When the US forces attack the mosque at that very moment they catch him off-guard while Marshall is wearing his beige suit when he enters the scene. ${ }^{42}$ The lines between both hemispheres are clearly drawn by this: Judging from the character's clothes you can tell the moral quality of his action-to-come.

The individual character traits are designed to further differentiate what the dress codes have set for a general context. So, the Turkish hero is presented as a man who has a hard cover but is soft and caring inside. He is shown to be serious and emotionally honest; being suggested to be the perfect protector and provider, both on the job and as a person. This is most significantly illustrated by the finale of the film. Although Alemdar shows a poker face for most of the film, which only mirrors the burden he shoulders on his job, he shares his anger, despair, and mourning with the outside world in this scene. Crouching on the ground he is holding the dying and the finally dead Leyla in his arms for about two and a half minutes, stroking her hair, clenching his fist in angry despair, crying badly and finally taking the golden blood-stained ring off Leyla's nose: ${ }^{43}$ She received this ring from her father, the Sheik, on her wedding day and was told by him not to take it off before she really felt free. ${ }^{44}$ Now Alemdar is doing this last service for the woman who has risked her life to save his life as death has "freed" her; whereas his US opponent Marshall has not hesitated to demonstrate his dis-respect for her and for women in general by shooting her into the heart twice at short distance. ${ }^{45}$

Within this context the Turkish hero's actions are legitimated by cases of violated honour: A man's honour can be violated because he feels to have failed in fulfilling his duty and responsibility in protecting others as is shown in the pre-titles sequence of the film. Resulting from this the moral concept shaping Alemdar is based on professional coolness: Alemdar sees his duty in answering his opponent's provocations by successfully pursuing the job he has been asked for. When Marshall tries to provoke him by pointing out how inferior the Turkish are compared to the Americans, he answers sharply in words but calmly in behaviour. ${ }^{46}$ The fact that he only rushes to violent fighting when this does not work out makes him the (moral) mastermind over his opponent's world.

In line with this Alemdar and his mates are presented as men of ideological integrity and as men bound by moral loyalties; the killings committed by them being suggested to be inevitable steps of self-defence, and being provoked by the opponent's attacks and wrong-doing; whereas the killings committed by Marshall and his men are seen as murders. Marshall is designed as a character who does not know (moral) loyalties: He counts on cooperation based on supposed win-win situations, payrolls, strict requirement to be of use and on absolute subordination to orders; for instance, using humanitarian aid and logistic support to lure allies in an attempt to rule over Iraq. ${ }^{47}$ From his perspective loyalties, fair play and honesty are weak spots in a real man's life and, therefore, obstacles in pursuing a mission. So, for instance, he does not hesitate to bring children into the hotel restaurant, which Alemdar has mined to put pressure on him. He knows Alemdar will not blow up a room with children in it, and he suggests that it is coward-like behaviour not to do so. ${ }^{48}$

Similar to Babel, the character drawing in Valley of Wolves - Iraq in this way conveys the general message of the film, i. e. that the real victims of the escalation caused by situations of a-symmetric cultural encounters are the integer, the peaceful and the scrupulous ones; in contrast to Babel, though, Valley of Wolves - Iraq generalizes this message from a context of individual behaviour to one of whole societies and cultures. 


\section{Conclusion}

In visualizing the causality of asymmetric cultural encounters and escalation created by the narrative of the film Babel relies on a narrative structure of parallel narrative strands illustrating the idea of cultural and communicative separation. The focus with character drawing is put on the characters' cultural and communicative in-competencies and on the situational context of the asymmetric cultural encounter in which they get involved and from which the escalation derives; the in-competencies being seen as rooting in the characters' individual backgrounds, and not in traditional ideas of cultural belonging.

Valley of Wolves - Iraq supports its narrative structure of face-to-face confrontations, which are arranged in an ideologically inverted East-West foe-and-hero pattern, by a detailed character drawing highlighting the central characters' incompatible codes of values and elevating the incompatibility of values to a level of universal relevance within a system of opposing cultural hemispheres in visualizing the causality of asymmetric cultural encounters and escalation.

Both films use the jump cut technique in supporting their narrative structures. Babel does so to support the visualization of the idea of cultural and communicative separation; Valley of Wolves - Iraq does so to intensify the effect of escalation processes and to integrate the fictitious characters' stories in historical reality. 
${ }^{1}$ For the reception of Valley of Wolves - Iraq (TR, 2006) with the European public see V. Bernard: Mutual Perceptions - A Look at the 2000-2010 State of East-West Discourse in Germany and Austria. In V. Bernard, S. Oksay, E. SensenigDabbous (Eds.): Breaking the Stereotype. From Orient and Occident to a Mutual Understanding of Images. Innsbruck: IUP 2011. pp. 21-46. For the reception of Babel (USA, 2006) see http://www.film-rezensionen.de/2009/10/babel/, http://de.wikipedia.org/wiki/Babel_(Film), http://www.filmstarts.de/kritiken/41034-Babel.html, http://www.kinokai.de/babel.150.22704.php, http://www.moviepilot.de/movies/babel-film/comments, http://www.amazon.de/Babel-Deluxe-Steelbook-DVDs/dp/B000NJM26S, http://www.filmzeit.de/Film/17415/BABEL/Kritik/, http://www.metacritic.com/movie/babel, http://www.imdb.com/title/tt0449467/, http://www.rottentomatoes.com/m/babel/, http://www.christiananswers.net/spotlight/movies/2006/babel2006.html, http://movies.nytimes.com/2006/10/27/movies/27babe.html, http://en.wikipedia.org/wiki/Babel (film), http://www.ofdb.de/review/101287,454583,Babel, http://movies.yahoo.com/movie/1808746699/info.

${ }^{2}$ For a definition of the term asymmetric conflict see http://en.wikipedia.org/wiki/Asymmetric_warfare.

${ }^{3}$ Babel (DVD). Directed by Alejandro González Iñárritu; screenplay by Guillermo Arriaga; produced by Alejandro González Iñárritu; Brad Pitt (Richard), Cate Blanchett (Susan), Said Tarchani (Ahmet), Gael Garcia Bernal (Santiago), Adriana Barraza (Amelia). An ANONYMOUS CONTENT, a ZETA FILM, a CENTRAL FILMS production copyright 2006, edited by Tobis Home Entertainment, 01:19:23-01:23:47.

${ }^{4}$ Ibid, 01:24-01:26.

${ }^{5}$ Ibid, 01:41-01:48:49.

${ }^{6}$ Ibid, 00:19:12-00:26:29; 00:43-00:44:23; 01:04-01:12; 01:36-01:39; 01:53-01:54.

${ }^{7}$ Ibid, 02:03:56-02:06:42.

${ }^{8}$ Ibid, 02:07.

${ }^{9}$ Ibid, 02:09-02:11.

${ }^{10}$ Ibid, 01:55.

${ }^{11}$ Ibid, 01:16:31-01:17; 01:39:07-01:40.

${ }^{12}$ In this incident twelve Turkish soldiers were held for 36 hours by US forces and had to wear sacks over their heads for all of this time. For more see: http://en.wikipedia.org/wiki/Hood_event.

${ }^{13}$ Kurtlar Vadisi - Irak/Valley of Wolves - Iraq/ KVI (DVD) Directed by Serdar Akar. Necati Şaşmaz (Polat Alemdar), Billy Zane (Sam William Marshall), Bergüzar Korel (Leyla), Gürkan Uygur (Memati), Kenan Çoban (Abdülhey), Erhan Ufak (Erhan), Chassan Massoud (Abdurrahman Halis Kerkuki), Diego Serrano (Dante). A Pana Film Production copyright 2006, edited by Koch Media, 00:00:17-00:08:08.

${ }^{14}$ For further details on the TV series see http://de.wikipedia.org/wiki/Tal_der_W\%C3\%B6lfe.

${ }^{15}$ KVI, 01:14:34-01:16:17.

${ }^{16}$ Ibid,00:15:23-00:17:52; 00:20:26.

${ }^{17}$ Ibid, 01:39:59.01:40:03.

${ }^{18}$ Ibid, 01:49:49-1:52:20.

${ }^{19}$ Ibid, 1:48:41-1:49:05; Leyla got this dagger from her husband on her wedding night to protect her honour (cf. KVI: 00:12:4600:13:09).

${ }^{20}$ Ibid, 01:47:20-01:47:28.

${ }^{21}$ For a definition of chaos theory see http://en.wikipedia.org/wiki/Chaos_theory.

${ }^{22}$ Babel, 02:09-02:11.

${ }^{23}$ Ibid, 00:09-00:10:18.

${ }^{24}$ Ibid, 02:02:24-02:03.

${ }^{25}$ KVI, 00:05:53-00:07:12.

${ }^{26}$ Ibid, 00:09:57-00:10:29. 
${ }^{27}$ Ibid, 00:15:25; 00:16:08.

${ }^{28}$ Ibid, 01:07:05-01:11:52.

${ }^{29}$ Ibid, 00:20-00:20:26;00:21-00:21:30.

${ }^{30}$ Babel, 00:36:54-00:38.

${ }^{31}$ Ibid, 00:38-00:42:46.

${ }^{32}$ Ibid, 00:04:25-00:04:45.

${ }^{33}$ Ibid, 00:06:30-00:06:56.

${ }^{34}$ Ibid, 00:07:56-00:08:49.

${ }^{35}$ Ibid, 00:14:16-00:16:00.

${ }^{36}$ Ibid, 00:39:40.

${ }^{37}$ Ibid, 01:58-02:00.

${ }^{38}$ Ibid, 01:00-01:02:54.

${ }^{39}$ KVI, 00:02:09; 00:20:27.

${ }^{40}$ Ibid, 01:34:03.

${ }^{41}$ Ibid, 01:38; 1:40:58.

${ }^{42}$ Ibid, 01:40:29.

${ }^{43}$ Ibid, 01:49:49-1:52:20.

${ }^{44}$ Ibid, 00:10:21.

${ }^{45}$ Ibid, 01:47:35.

${ }^{46}$ Ibid, 00:34:26-00:35:42.

${ }^{47}$ Ibid, 01:15:45-01:17:34.

${ }^{48}$ Ibid, 00:36:52-00:38:26.

Veronika Bernard (PhD) is an Associate Professor (Privatdozentin) with the Department of German language and literature at the University of Innsbruck and a member of the research platform CenT (Cultural Encounters and Transfer). She is one of the two directors of the IMAGES project (conferences, publications, exhibitions, online contests; www.images-1.over-blog.org) and has been the director of the project Breaking the Stereotype. Oriental and Occidental Stereotypes in the Course of Time (www.breaking-the-stereotype2009-2010.overblog.org). Veronika Bernard is a member of the advisory board of CINEJ Cinema Journal, the international refereed online cinema journal published by the University of Pittsburgh (http://cinej.pitt.edu).

She has earned her postdoctoral qualification (Habilitation) in German literature. Her doctoral thesis is on the Orient in $19^{\text {th }}$ century Austrian travel writings.

Her research interests are: cultural encounters in movies; migrant literature (German-Turkish authors); European views and stereotyping of the Orient; the city in literature.

She is the editor (with Serhan Oksay and Eugene Sensenig-Dabbous) of the book Breaking the Stereotype. From Orient and Occident to a Mutual Understanding of Images (Innsbruck: iup 2011).

For further publications see www.v-b-publikationen.over-blog.de.

e-mail: veronika.bernard@uibk.ac.at 